\title{
Improved survival in resected oesophageal and gastric adenocarcinomas over a decade: the Royal Marsden experience 2001-2010
}

\author{
Elisa Fontana ${ }^{1} \cdot$ Elizabeth C. Smyth $^{1} \cdot$ David Cunningham $^{1} \cdot$ Sheela Rao $^{1}$ • \\ David Watkins $^{1} \cdot$ William H. Allum $^{1} \cdot$ Jeremy Thompson $^{1} \cdot$ Tom Waddell $^{1}$. \\ Clare Peckitt $^{1} \cdot$ Ian Chau $^{1} \cdot$ Naureen Starling ${ }^{1}$
}

Received: 15 June 2015/Accepted: 18 October 2015/Published online: 5 November 2015

(C) The International Gastric Cancer Association and The Japanese Gastric Cancer Association 2015

\begin{abstract}
Background Oesophageal and gastric adenocarcinoma (OGA) treatment remains challenging. Improvements in early diagnosis, staging and management might have contributed to survival prolongation. To examine this hypothesis, we assessed outcomes of resected OGA patients in our institution over 10 years, comparing two time periods, 2001-2005 and 2006-2010.

Methods Records from patients who had undergone surgery with radical intent and follow-up for OGA were retrospectively reviewed. Patients followed up at hospitals other than the Royal Marsden Hospital were excluded. Two different cohorts were identified: patients with oesophageal and type I or type II oesophagogastric junction (OGJ) tumours, and patients with gastric and type III OGJ tumours.

Results We identified 360 patients: 147 from 2001-2005 and 213 from 2006-2010. The characteristics were comparable across the two time periods. Between 2001-2005 and 2006-2010, the percentage of R0 resections increased (from 67.1 to $81.1 \%$ for proximal tumours and from 76.3 to $95.9 \%$ for gastric and type III OGJ tumours). The mean number of lymph nodes retrieved increased over time. The 5 -year overall survival rate increased significantly from 42.3 to $56.6 \%$ for proximal tumours and from 38.8 to $55.3 \%$ for gastric and type III OGJ tumours. Similarly, the disease-free survival rate significantly increased from 34.6
\end{abstract}

Naureen Starling

naureen.starling@rmh.nhs.uk

Elisa Fontana

elisa.fontana@rmh.nhs.uk

1 Royal Marsden Hospital, Downs Road, Sutton SM2 5PT, UK to $53.5 \%$ for proximal tumours and from 35.9 to $51.1 \%$ for gastric and type III OGJ tumours.

Conclusion This study comprehensively describes the improvement in survival outcomes in a major UK referral centre over a 10 -year period, identifying potentially relevant factors such as increased number of $\mathrm{R} 0$ resections and higher lymph node yield.

Keywords Oesophageal adenocarcinoma .

Oesophagogastric junction adenocarcinoma - Gastric

adenocarcinoma $\cdot$ Surgical resection $\cdot$ Clinical management

\section{Introduction}

Oesophageal cancer and gastric cancer are, respectively, the eighth and fifth commonest types of malignancies worldwide [1]. With 107,300 deaths every year, gastric cancer is the fourth leading cause of cancer-related death globally [2]. In the UK, 8,300 new cases of oesophageal cancer (55\% adenocarcinoma) and more than 7,000 new cases of gastric cancer were diagnosed in 2011 [3]. The trends in incidence and mortality are divergent for oesophageal/oesophagogastric junction (OGJ) cancer and true gastric cancer. For distal or antral gastric cancer, mortality has decreased over the past 30 years, with an estimated annual percentage change of $-3.7 \%$ in men and $-3.4 \%$ in women, and a persisting favourable trend in mortality is predicted up to 2015 [4]. Eradication of Helicobacter pylori, cessation of smoking and improvement in food preservation and dietetic habits are factors that have been related to this decrease in incidence and mortality [4]. The opposite trend in incidence has been noted for the other anatomical subtype, OGJ cancer, the rates of which are steadily increasing, possibly related to an increased 
prevalence of obesity-related Barrett's oesophageal neoplasia [5].

Surgery remains the only potentially curative treatment for both gastric adenocarcinoma and oesophageal adenocarcinoma. However, because of poor rates of survival with a surgery-alone approach in locally advanced but resectable disease, and the fact that most patients in industrialised countries have locally advanced disease, combined treatment approaches are usually considered for disease of stage IB or greater [6, 7]. Evidence-based approaches for non-Asian patients include preoperative chemotherapy or chemoradiotherapy for proximal/OGJ tumours, or perioperative chemotherapy or postoperative chemoradiotherapy for both gastric cancer patients and oesophageal/OGJ cancer patients [8-12]. Adjuvant chemotherapy alone is supported by randomised trials in Asian patients but is seldom used in Western patients [13, 14]. However, selection of the optimal treatment approach is dependent on local practice, patient presentation and the characteristics of the underlying tumour for every patient.

Factors which influence the outcome of patients treated with curative intent for gastric cancer include improvements in imaging yielding a consequently more adequate disease staging, the increasingly pivotal role of multidisciplinary teams for treatment planning and the centralisation of surgery in high-volume centres. The largest cooperative population-based study of survival in oesophagogastric cancer, the EUROCARE-5 project, highlighted an increase from 23.3 to $25.1 \%$ in the 5-year relative survival rate for patients with gastric cancer diagnosed in the two 3-year periods 1999-2001 and 2005-2007 [15]. We hypothesised that changes in these variables may also have yielded improvements in overall survival in patients undergoing surgery during this period at the Royal Marsden Hospital (RMH), London, UK. To examine this hypothesis, we retrospectively collected data on resected oesophageal and gastric adenocarcinoma (OGA) patients over a decade. This analysis compares demographic, management and surgical outcomes according to the site of the primary tumour between two 5-year time periods: 2001-2005 and 2006-2010.

\section{Methods}

On the basis of surgical procedure codes, we identified all patients who underwent surgery for cancer of the oesophagus, OGJ or stomach at RMH between January 2001 and December 2010 from the hospital electronic patient record. Eligible patients had (1) a histological diagnosis of adenocarcinoma, (2) had curative-intent resection of the malignancy at RMH, (3) were 18 years or older, and (4) had postsurgical follow-up performed at RMH. Patients with histological diagnoses or unquestionable radiological evidence of metastatic disease before the date of surgery and patients for whom no data besides the date of surgery were available in the electronic patient record or for whom the date of surgery coincided with the last contact were excluded.

The data collected included patient demographics, the site of the primary tumour, preoperative computerised tomography (CT) staging, preoperative TN staging obtained by endoscopic ultrasonography (EUS) when performed, the type of surgery, the number of lymph nodes collected and the perioperative treatments received (including schedules and number of cycles for chemotherapy and the dose in grays and the fractions for radiotherapy). Histological details collected included pathological TNM stage, grade of differentiation and resection margins, defined as positive in the presence of tumour within $1 \mathrm{~mm}$ of the circumferential margin (CRM) [16]. On the basis of the date of surgery, two different cohorts were defined: patients from 2001-2005 and patients from 2006-2010. Considering the substantially different surgical approach between oesophageal and gastric cancer, we analysed demographic, management and outcomes according to the site of the primary tumour (type I and type II OGJ tumours vs gastric and type III OJG tumours, according to the Siewert classification) with descriptive statistics [17]. Disease-free survival, overall survival and survival beyond relapse were estimated by the Kaplan-Meier method; covariates were compared by the log-rank test and hazard ratios were calculated by Cox regression within the two time periods. Approval for this project was obtained before study commencement from the Institutional Review Board (Service Evaluation 3407).

\section{Results}

Approximately 600 patients underwent surgery for oesophageal or gastric cancer at RMH between 2001 and 2010. After exclusion of patients with tumour histological type different from adenocarcinoma and patients who had palliative surgery or were followed up at a hospital other than RMH, 360 eligible patients were identified for the analysis. Of these, 147 underwent surgery during the first time period (2001-2005) and 213 underwent surgery during the second time period (2006-2010) (Fig. 1).

\section{Characteristics of patients}

Approximately half of the patient population had a primary tumour localised at the OGJ, $40 \%$ in the stomach and less than $10 \%$ had a lower oesophageal adenocarcinoma; the proportion of patients with type III OGJ tumours and 


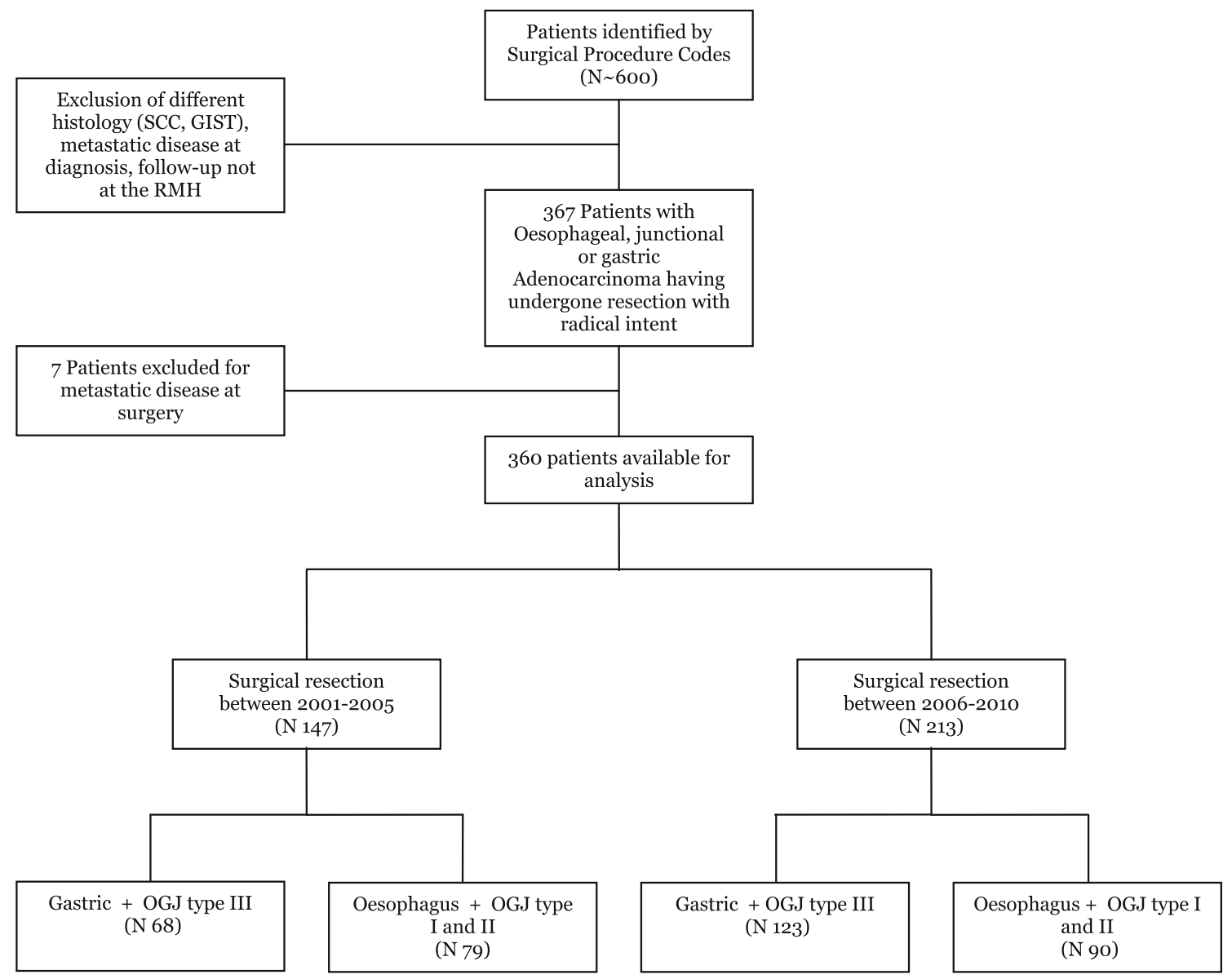

Fig. 1 Selection of patients. GIST gastrointestinal stromal tumour, OGJ oesophagogastric junction, RMH Royal Marsden Hospital, SCC squamous cell carcinoma

gastric tumours increased over time. Patients with lower oesophageal cancer or type I and type II OGJ cancer were younger and more frequently male than patients with type III OGJ cancer and gastric cancer. Most of the patients had an Eastern Cooperative Oncology Group performance status of $0-1$. These baseline characteristics were comparable across the two time periods (Table 1).

\section{Tumour staging}

Preoperative staging is detailed in Table 2. In the oesophageal and type I and type II OGJ cancer population, the use of EUS for preoperative $\mathrm{T}$ and $\mathrm{N}$ category definition increased over time, from 72 to $83 \%$. Overall, almost $60 \%$ of patients had a T3-T4 tumour and more than $60 \%$ had lymph node involvement.

In the gastric cancer cohort, the proportion of patients with preoperative $\mathrm{CT}$ stage $\mathrm{T} 1-\mathrm{T} 2$ cancer significantly increased over time, from 13 to $40 \%$. Approximately $50 \%$ did not demonstrate preoperative lymph node involvement on CT. The use of positron emission tomography (PET)-CT as a further staging technique also significantly increased over time for both anatomical tumour locations, extending to $46 \%$ of oesophageal and type I and type II OGJ tumours in the later time period.

\section{Clinical management}

Treatments and pathological findings are detailed in Table 3. Most patients received neoadjuvant or perioperative chemotherapy. In exceptional circumstances, a nonstandard adjuvant approach was adopted, mainly due to patients' choice or comorbidities, or alternatively when emergency surgery was required or after surgical upstaging. There was a significant increase in the proportion of patients treated with a perioperative approach over time, whereas the use of neoadjuvant chemotherapy alone declined over time.

The surgical approach consisted of Ivor Lewis oesophagogastrectomy for the most of the oesophageal and type I and type II OGJ cancer patients. In the gastric and type III OGJ cancer population, most patients underwent distal 
Table 1 Patient characteristics according to the site of the primary tumour and the period of surgery

\begin{tabular}{|c|c|c|c|c|c|c|}
\hline \multirow[t]{2}{*}{ Characteristics } & \multicolumn{3}{|c|}{ Oesophagus and OGJ, types I and II } & \multicolumn{3}{|c|}{ Stomach and OGJ, type III } \\
\hline & $\begin{array}{l}\text { Surgery between } \\
2001 \text { and } 2005\end{array}$ & $\begin{array}{l}\text { Surgery between } \\
2006 \text { and } 2010\end{array}$ & $P$ & $\begin{array}{l}\text { Surgery between } \\
2001 \text { and } 2005\end{array}$ & $\begin{array}{l}\text { Surgery between } \\
2006 \text { and } 2010\end{array}$ & $P$ \\
\hline Total patients & 79 & 90 & & 68 & 123 & \\
\hline Age (years) & & & 0.317 & & & 0.264 \\
\hline Median & 64 & 62 & & 70 & 67 & \\
\hline Range & $42-81$ & $33-83$ & & $24-84$ & $39-89$ & \\
\hline Sex & & & 0.52 & & & 0.681 \\
\hline Male & $71(89.9 \%)$ & $78(86.7 \%)$ & & $50(73.5 \%)$ & $87(70.7 \%)$ & \\
\hline Female & $8(10.1 \%)$ & $12(13.3 \%)$ & & $18(26.5 \%)$ & $36(29.3 \%)$ & \\
\hline Ethnicity & & & $0.030^{\mathrm{b}}$ & & & $0.182^{\mathrm{b}}$ \\
\hline Afro-Caribbean & $0(0 \%)$ & $1(1.1 \%)$ & & $3(4.4 \%)$ & $10(8.1 \%)$ & \\
\hline East Asian & $0(0 \%)$ & $2(2.2 \%)$ & & $1(1.5 \%)$ & $6(4.9 \%)$ & \\
\hline Indian subcontinent & $1(1.3 \%)$ & $0(0 \%)$ & & $5(7.4 \%)$ & $2(1.6 \%)$ & \\
\hline Western & $77(97.4 \%)$ & $80(88.9 \%)$ & & $58(85.3 \%)$ & $95(77.2 \%)$ & \\
\hline Not recorded & $1(1.3 \%)$ & $7(7.8 \%)$ & & $1(1.5 \%)$ & $10(8.1 \%)$ & \\
\hline Performance status & & & $0.041^{\mathrm{c}}$ & & & $0.491^{\mathrm{c}}$ \\
\hline 0 & $16(20.3 \%)$ & $33(36.7 \%)$ & & $13(19.1 \%)$ & $36(29.3 \%)$ & \\
\hline 1 & $26(32.9 \%)$ & $24(26.7 \%)$ & & $19(27.9 \%)$ & $41(33.3 \%)$ & \\
\hline 2 & $1(1.3 \%)$ & $0(0 \%)$ & & $4(5.9 \%)$ & $7(5.7 \%)$ & \\
\hline Not recorded & $36(45.6 \%)$ & $33(36.7 \%)$ & & $32(47.1 \%)$ & $39(31.7 \%)$ & \\
\hline \multicolumn{7}{|l|}{ Site of primary tumour } \\
\hline Oesophagus & $17(21.5 \%)$ & $12(13.3 \%)$ & & & & \\
\hline OGJ, type I & $35(44.3 \%)$ & $42(46.7 \%)$ & & & & \\
\hline OGJ, type II & $27(34.2 \%)$ & $36(40 \%)$ & & & & \\
\hline OGJ, type III & & & & $14(20.6 \%)$ & $31(25.2 \%)$ & \\
\hline Stomach & & & & $54(79.4 \%)$ & $92(74.8 \%)$ & \\
\hline Elevated levels of tumour markers ${ }^{\mathrm{a}}$ & & & 0.329 & & & 0.579 \\
\hline Yes & $19(24.1 \%)$ & $26(28.9 \%)$ & & $13(19.1 \%)$ & $30(24.4 \%)$ & \\
\hline No & $49(62.0 \%)$ & $47(52.2 \%)$ & & $26(38.2 \%)$ & $75(61 \%)$ & \\
\hline Unknown & $11(13.9 \%)$ & $17(18.9 \%)$ & & $29(42.7 \%)$ & $18(14.6 \%)$ & \\
\hline
\end{tabular}

$O G J$ oesophagogastric junction

${ }^{a}$ Either carcinoembryonic antigen or CA 19-9 or both at presentation

b Western versus others in the 2001-2005 group versus the 2006-2010 group according to the site of the primary tumour

c Performance status 0 versus performance status 1-2 in the 2001-2005 group versus the 2006-2010 group according to the site of the primary tumour

subtotal or total gastrectomy. No significant difference was observed in the surgical approach between the two time periods. The mean number of lymph nodes collected significantly increased over time in both cohorts (Fig. 2). In oesophageal and type I and type II OGJ tumours, the 30and 90-day mortality rates were not statistically different between the two time periods ( 1.3 and $3.8 \%$, respectively, in 2001-2005 and 1.1 and $3.3 \%$, respectively, in 2006-2010). A significant difference over time was identified in the gastric and type III OGJ cancer group: the 30and 90-day mortality rates were, respectively, 10.3 and $14.7 \%$ in $2001-2005$ and 0 and $1.6 \%$ in 2006-2010.

\section{Pathological findings}

The percentage of $\mathrm{R} 1$ resections decreased over time in both populations. In oesophageal and type I and type II OGJ tumours it decreased from 28 to $19 \%$; in almost all specimens the margin involved was the circumferential one (26\% in 2001-2005 vs $18 \%$ in 2006-2010). In gastric and type III OGJ tumours, the R1 resection rate decreased from 14 to $4 \%$; in most cases, the margin involved was the longitudinal one (10\% in 2001-2005 vs $2 \%$ in 2006-2010).

Overall, oesophageal and type I and type II OGJ tumours were more frequently found to be of a more 
Table 2 Preoperative staging according to the site of the primary tumour and the period of surgery

\begin{tabular}{|c|c|c|c|c|c|c|c|c|c|c|}
\hline \multirow[t]{3}{*}{ Characteristics } & \multicolumn{5}{|c|}{ Oesophagus and OGJ, types I and II } & \multicolumn{5}{|c|}{ Stomach and OGJ, type III } \\
\hline & \multicolumn{2}{|l|}{$\begin{array}{l}\text { Surgery between } \\
2001 \text { and } 2005\end{array}$} & \multicolumn{2}{|l|}{$\begin{array}{l}\text { Surgery between } \\
2006 \text { and } 2010\end{array}$} & \multirow[t]{2}{*}{$P$} & \multicolumn{2}{|c|}{$\begin{array}{l}\text { Surgery between } 2001 \\
\text { and } 2005\end{array}$} & \multicolumn{2}{|l|}{$\begin{array}{l}\text { Surgery between } \\
2006 \text { and } 2010\end{array}$} & \multirow[t]{2}{*}{$P$} \\
\hline & No. of patients & $\%$ & No. of patients & $\%$ & & No. of patients & $\%$ & No. of patients & $\%$ & \\
\hline Total patients & 79 & & 90 & & & 68 & & 123 & & \\
\hline CT T category & & & & & $0.932^{\mathrm{a}}$ & & & & & $0.001^{\mathrm{a}}$ \\
\hline $\mathrm{T} 1-\mathrm{T} 2$ & 11 & 13.9 & 13 & 14.4 & & 9 & 13.3 & 50 & 40.7 & \\
\hline T3-T4 & 44 & 55.7 & 50 & 55.6 & & 30 & 44.1 & 39 & 31.7 & \\
\hline $\mathrm{TX}$ & 7 & 8.9 & 15 & 16.7 & & 16 & 23.5 & 16 & 13 & \\
\hline Unknown & 17 & 21.5 & 12 & 13.3 & & 13 & 19.1 & 18 & 14.6 & \\
\hline CT $\mathrm{N}$ category & & & & & 0.746 & & & & & 0.114 \\
\hline No & 33 & 41.8 & 39 & 43.3 & & 33 & 48.5 & 56 & 45.5 & \\
\hline $\mathrm{N} 1-\mathrm{N} 2$ & 28 & 35.4 & 37 & 41.1 & & 16 & 23.5 & 48 & 39 & \\
\hline Unknown & 18 & 22.8 & 14 & 15.6 & & 19 & 27.9 & 19 & 15.5 & \\
\hline Baseline EUS performed & 57 & 72.2 & 75 & 83.3 & 0.079 & & & & & \\
\hline EUS T category & & & & & $0.068^{\mathrm{a}}$ & & & & & \\
\hline $\mathrm{T} 1$ & 2 & 3.5 & 7 & 9.3 & & & & & & \\
\hline $\mathrm{T} 2$ & 9 & 15.8 & 18 & 24 & & & & & & \\
\hline $\mathrm{T} 3-\mathrm{T} 4$ & 44 & 77.1 & 47 & 62.7 & & & & & & \\
\hline $\mathrm{TX}$ & 1 & 1.8 & 1 & 1.3 & & & & & & \\
\hline Unknown & 1 & 1.8 & 2 & 2.7 & & & & & & \\
\hline EUS $\mathrm{N}$ category & & & & & 0.318 & & & & & \\
\hline No & 20 & 35.1 & 19 & 25.3 & & & & & & \\
\hline N1 & 35 & 61.4 & 49 & 65.3 & & & & & & \\
\hline Unknown & 2 & 3.5 & 7 & 9.3 & & & & & & \\
\hline EUS/CT concordance & & & & & 1 & & & & & \\
\hline Yes & 22 & 38.6 & 30 & 40 & & & & & & \\
\hline No & 22 & 38.6 & 30 & 40 & & & & & & \\
\hline Unknown & 13 & 22.8 & 15 & 20 & & & & & & \\
\hline Baseline PET performed & & & & & $<0.001$ & & & & & 0.001 \\
\hline Yes & 12 & 15.2 & 46 & 51.1 & & 2 & 2.9 & 33 & 26.8 & \\
\hline FDG avid & 9 & 75 & 42 & 91.3 & & 2 & 100 & 24 & 72.7 & \\
\hline
\end{tabular}

$C T$ computed tomography, EUS endoscopic ultrasonography, $F D G$ fluorodeoxyglucose, $O G J$ oesophagogastric junction, $P E T$ positron emission tomography

a T1-T2 versus T3-T4 in the 2001-2005 group versus the 2006-2010 group according to the site of the primary tumour

advanced pathological $\mathrm{T}$ category than gastric and type III OGJ tumours; there was a trend towards a higher proportion of early-stage $\mathrm{T}$ category cancers resected in the later time period for both subsites. More than $50 \%$ of patients who underwent surgery in the later time period (2006-2010) regardless of the site of the primary tumour did not demonstrate lymph node involvement.

\section{Survival outcomes}

At the time of analysis, the median follow-up time was 95.5 months $[95 \%$ confidence interval (CI) 73.9-112.2 months] for patients who underwent surgery in the first time period (2001-2005) and 58.6 months (95\% CI 54.2-60.6 months) for those who underwent surgery in the second time period (2006-2010). Survival outcomes according to the site of the primary tumour and the time period are shown in Table 4.

In the earlier time period group (2001-2005), 67 of 147 patients $(45.6 \%)$ experienced a relapse. The presence of an anastomotic relapse as a single site of relapse was confirmed in $3 \%$ of the population. No significant difference was demonstrated in the pattern of relapse (anastomotic only vs any other site) in both cohorts over time. Almost $50 \%$ of patients who experienced a relapse were treated with at least one cycle of first-line palliative chemotherapy 
Table 3 Treatment and pathological details according to the site of the primary tumour and the period of surgery

\begin{tabular}{|c|c|c|c|c|c|c|c|c|c|c|}
\hline \multirow[t]{3}{*}{ Characteristics } & \multicolumn{5}{|c|}{ Oesophagus and OGJ, types I and II } & \multicolumn{5}{|c|}{ Stomach and OGJ, type III } \\
\hline & \multicolumn{2}{|c|}{$\begin{array}{l}\text { Surgery between } \\
2001 \text { and } 2005\end{array}$} & \multicolumn{2}{|c|}{$\begin{array}{l}\text { Surgery between } \\
2006 \text { and } 2010\end{array}$} & \multirow[t]{2}{*}{$P$} & \multicolumn{2}{|c|}{$\begin{array}{l}\text { Surgery between } \\
2001 \text { and } 2005\end{array}$} & \multicolumn{2}{|c|}{$\begin{array}{l}\text { Surgery between } \\
2006 \text { and } 2010\end{array}$} & \multirow[t]{2}{*}{$P$} \\
\hline & $\begin{array}{l}\text { No. of } \\
\text { patients }\end{array}$ & $\%$ & $\begin{array}{l}\text { No. of } \\
\text { patients }\end{array}$ & $\%$ & & $\begin{array}{l}\text { No. of } \\
\text { patients }\end{array}$ & $\%$ & $\begin{array}{l}\text { No. of } \\
\text { patients }\end{array}$ & $\%$ & \\
\hline Total patients & 79 & & 90 & & & 68 & & 123 & & \\
\hline Surgery & & & & & $0.207^{\mathrm{c}}$ & & & & & $0.580 *$ \\
\hline $\begin{array}{l}\text { Ivor Lewis } \\
\text { oesophogastrectomy }\end{array}$ & 77 & 97.5 & 84 & 93.3 & & 6 & 8.8 & 14 & 11.3 & \\
\hline Total gastrectomy & 2 & 2.5 & 6 & 6.7 & & 27 & 39.8 & 51 & 41.5 & \\
\hline Subtotal gastrectomy & & & & & & 35 & 51.4 & 58 & 47.2 & \\
\hline Resection & & & & & 0.116 & & & & & 0.005 \\
\hline $\mathrm{R} 0$ & 53 & 67.1 & 73 & 81.1 & & 52 & 76.5 & 118 & 95.9 & \\
\hline $\mathrm{R} 1$ & 22 & 27.8 & 17 & 18.9 & & 10 & 14.7 & 5 & 4.1 & \\
\hline Unknown & 4 & 5.1 & 0 & 0 & & 6 & 8.8 & 0 & 0 & \\
\hline Grade & & & & & $0.354^{\mathrm{d}}$ & & & & & $0.178^{\mathrm{d}}$ \\
\hline Poor & 39 & 49.4 & 41 & 42.2 & & 46 & 67.7 & 75 & 61 & \\
\hline Moderate & 29 & 36.7 & 38 & 45.6 & & 18 & 26.5 & 42 & 34.2 & \\
\hline Good & 2 & 2.5 & 6 & 6.7 & & 0 & 0 & 4 & 3.3 & \\
\hline Unknown & 9 & 11.4 & 5 & 5.6 & & 4 & 5.9 & 2 & 1.6 & \\
\hline Tumour $\mathrm{T}$ category & & & & & $0.043^{\mathrm{e}}$ & & & & & $0.167^{\mathrm{e}}$ \\
\hline T0 & 3 & 3.8 & 6 & 6.7 & & 3 & 4.4 & 6 & 4.9 & \\
\hline $\mathrm{T} 1-\mathrm{T} 2$ & 32 & 40.5 & 49 & 54.4 & & 37 & 54.5 & 83 & 67.5 & \\
\hline T3-T4 & 42 & 53.2 & 35 & 38.9 & & 24 & 35.3 & 34 & 27.6 & \\
\hline $\mathrm{TX}$ & 2 & 2.5 & 0 & 0 & & 4 & 5.8 & 0 & 0 & \\
\hline Nodal status & & & & & 0.57 & & & & & 0.169 \\
\hline No & 39 & 49.4 & 49 & 54.4 & & 26 & 38.2 & 63 & 51.2 & \\
\hline $\mathrm{N} 1-\mathrm{N} 3$ & 38 & 48.1 & 40 & 44.4 & & 38 & 55.9 & 60 & 48.8 & \\
\hline Unknown & 2 & 2.5 & 1 & 1.1 & & 4 & 5.9 & 0 & 0 & \\
\hline Perioperative treatment & & & & & $0.012^{\mathrm{f}}$ & & & & & $0.016^{\mathrm{f}}$ \\
\hline Adjuvant $^{\mathrm{a}}$ & 2 & 2.5 & 0 & 0 & & 5 & 7.4 & 5 & 4.1 & \\
\hline Neoadjuvant & 61 & 77.2 & 46 & 51.1 & & 22 & 32.4 & 26 & 21.1 & \\
\hline Perioperative $^{\mathrm{b}}$ & 9 & 11.4 & 23 & 25.6 & & 13 & 19.1 & 62 & 50.4 & \\
\hline None & 7 & 8.9 & 21 & 23.3 & & 28 & 41.2 & 30 & 24.4 & \\
\hline
\end{tabular}

OGJ oesophagogastric junction

a Because to patients' choice (3), emergency surgery (2), surgical upstaging (3) and comorbidities (4)

b Nineteen patients received postsurgical chemoradiotherapy, 18 OGJ cancer patients and one gastric cancer patient because of R1 resection; two OGJ cancer patients received presurgical chemoradiotherapy because of tumour burden persistence

c Oesophagogastrectomy versus the others in the 2001-2005 group versus the 2006-2010 group according to the site of the primary tumour

d Poor versus the others in the 2001-2005 group versus the 2006-2010 group according to the site of the primary tumour

e T0-T2 versus T3-T4 in the 2001-2005 group versus the 2006-2010 group according to the site of the primary tumour

f None versus any other adjunct treatment in the 2001-2005 group versus the 2006-2010 group according to the site of the primary tumour

and $14(20.1 \%)$ were treated with a second-line treatment. In the later time period group (2006-2010), 80 of 213 patients $(37.6 \%)$ experienced a relapse. Of these, 50 patients $(62.5 \%)$ were treated with at least one cycle of first-line palliative chemotherapy and $17(21.2 \%)$ also received a second-line treatment. One patient in the earlier time period group and five patients in the later time period group received a third-line treatment.

Fifty-three percent of the population died $(54.6 \%$ of oesophageal and type I and type II OGJ cancer patients and $50 \%$ of gastric cancer patients). The 5-year overall survival rate significantly increased over time in both 
Fig. 2 Number of lymph nodes collected by year

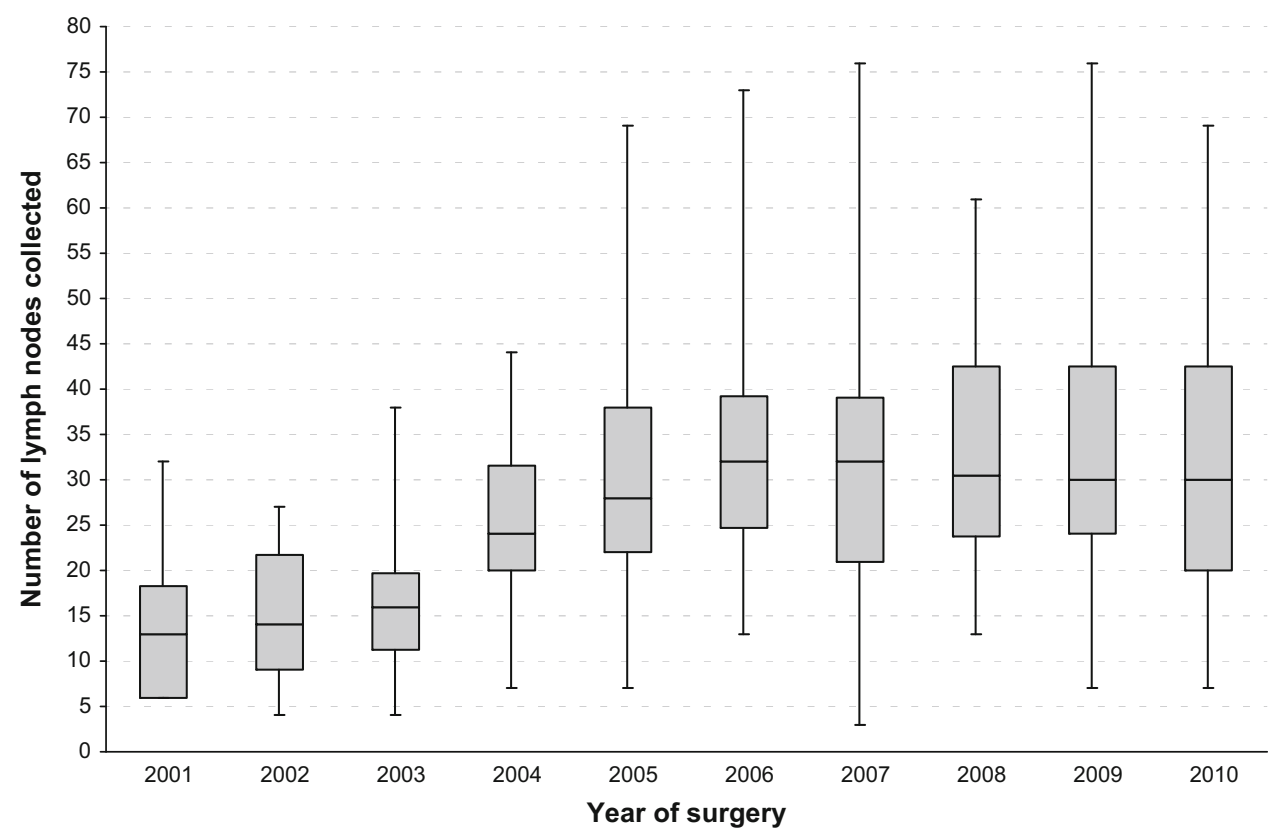

cohorts: from 42.3 to $56.6 \%$ [hazard ratio 0.64 (95\% CI $0.41-0.98), P=0.040]$ for oesophageal and type I and type II OGJ cancer patients and from 38.8 to $55.3 \%$ [hazard ratio $0.51(95 \% \mathrm{CI} 0.34-0.76), P=0.001$ ] for gastric and type III OGJ cancer patients. Similarly, the 5-year disease-free survival rate significantly increased over time in both cohorts: from 34.6 to $53.5 \%$ [hazard ratio 0.61 (95\% CI 0.41-0.92), $P=0.019$ ] for oesophageal and type I and type II OGJ cancer patients and from 35.9 to $51.1 \%$ [hazard ratio 0.56 (95 \% CI $0.38-0.82$ ), $P=0.003$ ] for gastric and type III OGJ cancer patients (Fig. 3). The survival time from relapse to the last followup was between 8 and 10 months for oesophageal and type I and type II OGJ cancer patients and 6 months for gastric and type III OGJ cancer patients. No significant improvement was demonstrated over time.

\section{Discussion}

In this study we examined patient and tumour characteristics, preoperative staging, treatment and outcomes of a large cohort of patients with gastric and gastroesophageal cancers selected from a single cancer centre over a period of 10 years. We then analysed any differences in treatment pathways and survival over two 5-year periods: 2001-2005 and 2006-2010. Our findings demonstrate a significant improvement in disease-free and overall survival in the later time period. We postulate that the significant increase in the number of R0 resections and the higher lymph node yield are the main factors affecting outcomes. As advances in surgical techniques do not always translate into significant differences in outcomes, we speculate that improved patient selection for those truly amenable to curative resection and exclusion of those patients making rapid progress with neoadjuvant treatment may also be partly responsible for these results. However, this contribution remains speculative because of the nature of this study, which did not allow the description of stage migration phenomena.

Changes in the pattern of the use of chemotherapy as an adjunctive treatment might also contribute to improved outcomes. This large dataset is reflective of the practice at $\mathrm{RMH}$, which is a major tertiary referral cancer centre. The population served by RMH is diverse and is broadly representative of the UK population as a whole. Several practice-changing clinical trials were ongoing during the decade under investigation, and this activity might have impacted on both management and outcomes. When the Medical Research Council OE02 study was reported in 2002 [18], the strategy adopted for patients with lowerthird oesophageal or cardia tumours consisted of two cycles of preoperative cisplatin and 5-fluorouracil chemotherapy. From November 2004, the same population was eligible for the Medical Research Council OE05 trial [19], which randomised patients to receive either two cycles of cisplatin and 5-fluorouracil chemotherapy or four cycles of epirubicin, cisplatin, and capecitabine chemotherapy. Following the publication of the UK Medical Research Council MAGIC trial in 2006, perioperative chemotherapy for tumours staged as $\mathrm{T} 2$ or greater became a standard treatment for both gastric and lower-third oesophageal adenocarcinomas [10]. Finally, in October 2007 a further multicentre study for patients with operable 


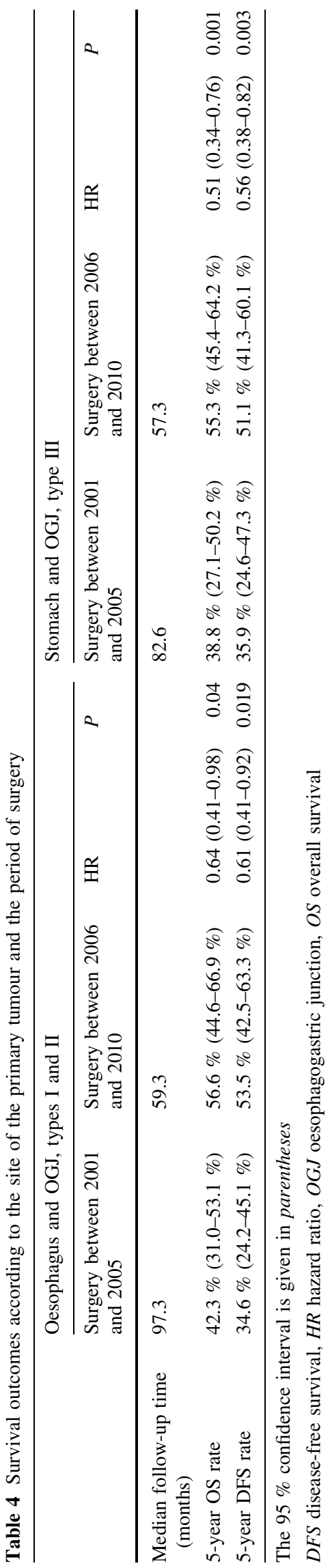

oesophagogastric adenocarcinoma, the Medical Research Council ST03 trial, which randomised patients to receive perioperative epirubicin, cisplatin, and capecitabine chemotherapy with or without bevacizumab therapy, opened for recruitment [20]. Participation of patients in these studies contributed to promotion of an adjunctive perioperative chemotherapy strategy; this is supported by the fact that both in $70 \%$ of patients the cancer was staged as greater than $\mathrm{T} 2$ and the same proportion received at least a preoperative treatment. We acknowledge that patients may experience superior outcomes in a researchactive environment [21]. Therefore, it is possible that the high levels of research activity at RMH may result in longer survival for patients, not just those who are participants in clinical trials; however, this would apply equally across both time periods.

With respect to preoperative staging, an increase in the proportion of early-stage tumours was noted in both groups over time, reaching statistical significance in the gastric cancer cohort. We hypothesise that the increased use of PET-CT might be contributory in excluding patients with occult advanced disease, leading to selection of patients with earlier-stage disease as candidates for surgery. However, as PET-CT did not become a standard of care in our institution until 2009, it is difficult to estimate its effect on stage migration and survival without an analysis of prePET and post-PET time periods, which may be confounded by other variables. The percentage of EUS performed at the baseline in the proximal cancer cohort also significantly increased over time. A more accurate definition of the depth of tumour invasion and local lymph node involvement might have contributed to changes in decision making regarding adoption of a preoperative treatment strategy or surgery alone. As intention-to-treat data were not collected in this study, we cannot accurately determine the potential impact of the increased use of EUS on treatment decisions.

No significant difference in the type of surgery performed was demonstrated. However, surgical outcomes changed significantly over time; specifically, a higher lymph node yield was demonstrated in the later time period. Furthermore, the rate of R0 resections for patients with gastric and type III OGJ tumours dramatically increased from 76.5 to $95.9 \%$ over time. These data compare favourably with the National Oesophago-gastric Cancer Audit 2013 data [22]. Although not statistically significant, an increase in the $\mathrm{R} 0$ resection rate in the group of patients with proximal tumours was demonstrated, from 67.1 to $81.1 \%$. In most cases the CRM was involved, in 26 and $18 \%$ of cases in the earlier and later periods, respectively. These figures are consistent with the National Oesophagogastric Cancer Audit 2013, which reported a CRM rate of $27 \%$ [22]. The involvement of the CRM is clearly a major 
Fig. 3 Survival outcomes. OGJ oesophagogastric junction
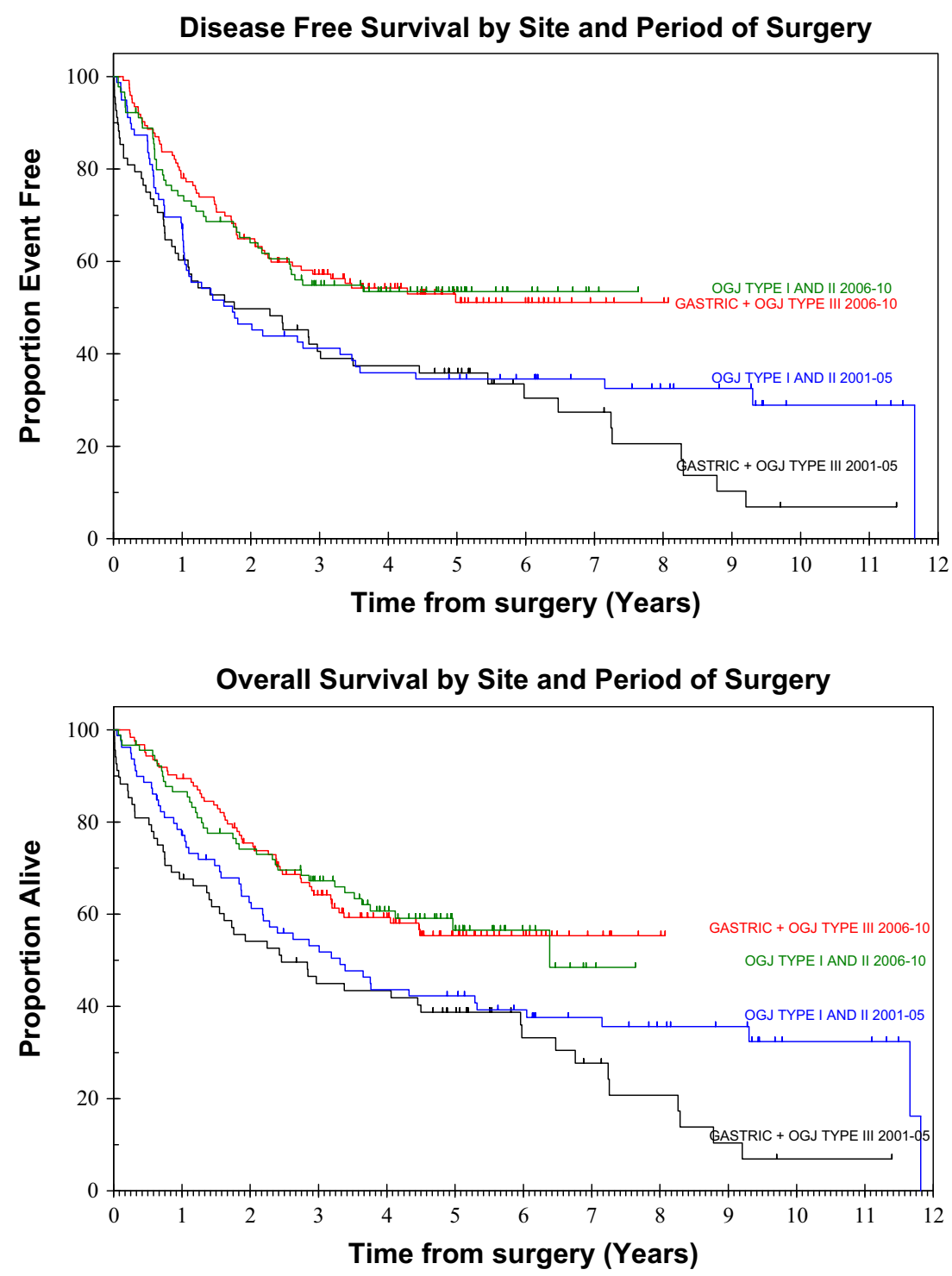

challenge in oesophageal and OGJ tumours. As such, introduction of preoperative chemoradiotherapy regimens such as that used in the CROSS trial is a rational and effective approach in the treatment of these tumours [9].

Service provision for oesophagogastric cancer in the UK underwent a major reconfiguration over the past decade, following publication of the Department of Health's document entitled "Guidance on Commissioning Cancer Services: Improving Outcomes in Upper Gastro-intestinal Cancers" [23]. In 2002, national guidelines for the management of this disease were introduced, with specific recommendations in terms of diagnosis, staging, pathology report and treatment [24]. A concerted effort was made to centralise specialised cancer surgery in high-volume centres, where multidisciplinary teams are responsible for patient management. As a consequence, the number of patients referred to specialised centres such as RMH may have increased and consolidated the experience of the multidisciplinary team there. Furthermore, in 2004, the Joint Advisory Group on Gastrointestinal Endoscopy [25] provided dedicated guidelines for training, appraisal and assessment of trainees in gastrointestinal endoscopy. This may also have contributed to improvements in the national endoscopy service, with consequent increases in early detection of cancer, as suggested by the significant increase in the proportion of early-stage cancer patients.

In the case of recurrent cancer following surgery, median survival improved over time for proximal tumours, without reaching statistical significance. In the later time period, approximately two thirds of patients received treatment on relapse, whereas this proportion was lower in the earlier time period. On the basis of the COUGAR-02 study, second-line chemotherapy was not adopted as a standard RMH practice until 2012, although selected 
patients did receive it before then [26]. Additionally, the monoclonal antibody trastuzumab used in the treatment of human epidermal growth factor receptor 2 positive disease was not available in the UK until 2011, and only two patients in this study received it in a first-line metastatic setting [27]. Owing to the increasing availability of these treatments, it is likely that there has now been a further improvement in postrelapse survival over time, although the treatment intent currently remains palliative in this setting.

This study has a number of limitations principally because of the retrospective nature of the data collection. This has prevented our accurately identifying the total number of cases evaluated over the study period, which does not allow us to report the surgical resection rate. However, the results do demonstrate the outcome for a large cohort of patients considered fit for radical treatment (performance status less than 2) with locally operable disease. Using the comparison of the two time-period groups as an internal control, we have demonstrated improved outcomes over time in the selected population. All comparisons in this analysis were made between the average of variables considered from the two consecutive time periods. As a result, differences in management and outcomes between the two tails of the decade might be underestimated; limiting our analysis to these restrictive time points would reduce our power to draw statistically sound conclusions. During the study, neoadjuvant or perioperative chemotherapy became the standard UK practice for treatment of oesophageal and gastric cancer. Recent data from the CROSS trial have demonstrated higher R0 resection rates with a chemoradiotherapy regimen compared with surgery alone. We acknowledge the issue of the most appropriate perioperative management remains to be fully established and that the UK practice may change in relation to cases with a threatened CRM [9].

In conclusion, the findings of this study demonstrate that survival of patients with resected OGJ adenocarcinoma at RMH improved during the decade from 2001 to 2010. Relevant factors may include an increase in the R0 resection rate and a progressively higher lymph node yield. A more accurate staging of the disease preoperatively by the use of CT-PET and EUS, leading to exclusion from surgery of those patients with CT-occult metastatic disease, and an increase in chemotherapy use as a surgical adjunct may also be contributory. Clinically, ongoing expert multidisciplinary team input is essential to maintain this quality of care. Although oesophageal and gastric cancer remain lethal diseases, this is currently an area of intense research and improvements in survival are anticipated. The results recently published by The Cancer Genome Atlas Research Network [28] have contributed to a better understanding of tumour biology and molecular profiles, and it is hoped that this will promote the identification of prognostic and predictive biomarkers fundamental in personalisation of the chemotherapeutic and surgical pathway for this disease.

Acknowledgments We acknowledge support from the National Institute for Health Research Royal Marsden/Institute of Cancer Research Biomedical Research Centre.

\section{Compliance with ethical standards}

Ethical standards All procedures followed were in accordance with the ethical standards of the responsible committee on human experimentation (institutional and national) and with the Helsinki Declaration of 1964 and later versions. Approval for this project was obtained before study commencement from the Institutional Review Board (Service Evaluation 3407).

Conflict of interest The authors declare that they have no conflict of interest.

\section{References}

1. Ferlay J, Soerjomataram I, Dikshit R, Eser S, Mathers C, Rebelo $\mathrm{M}$, et al. Cancer incidence and mortality worldwide: sources, methods and major patterns in GLOBOCAN 2012. Int J Cancer. 2015;136(5):E359-86

2. Ferlay J, Steliarova-Foucher E, Lortet-Tieulent J, Rosso S, Coebergh JW, Comber $\mathrm{H}$, et al. Cancer incidence and mortality patterns in Europe: estimates for 40 countries in 2012. Eur J Cancer. 2013;49(6):1374-403.

3. Cancer Research UK. Oesophageal cancer incidence statistics I Cancer Research UKhttp://www.cancerresearchuk.org/cancerinfo/cancerstats/types/oesophagus/incidence/uk-oesophageal-can cer-incidence-statistics\#source1 (2015). Accessed 2 Jan 2015.

4. Ferro A, Peleteiro B, Malvezzi M, Bosetti C, Bertuccio P, Levi F, et al. Worldwide trends in gastric cancer mortality (1980-2011), with predictions to 2015, and incidence by subtype. Eur J Cancer. 2014;50(7):1330-44.

5. Shah MA, Kelsen DP. Gastric cancer: a primer on the epidemiology and biology of the disease and an overview of the medical management of advanced disease. J Natl Compr Canc Netw. 2010;8(4):437-47.

6. Washington K. 7th edition of the AJCC cancer staging manual: stomach. Ann Surg Oncol. 2010;17(12):3077-9.

7. Waddell T, Verheij M, Allum W, Cunningham D, Cervantes A, Arnold D. Gastric cancer: ESMO-ESSO-ESTRO clinical practice guidelines for diagnosis, treatment and follow-up. Eur J Surg Oncol. 2014;40(5):584-91.

8. Allum WH, Stenning SP, Bancewicz J, Clark PI, Langley RE. Long-term results of a randomized trial of surgery with or without preoperative chemotherapy in esophageal cancer. J Clin Oncol. 2009;27(30):5062-7.

9. van Hagen P, Hulshof MC, van Lanschot JJ, Steyerberg EW, van Berge Henegouwen MI, Wijnhoven BP, et al. Preoperative chemoradiotherapy for esophageal or junctional cancer. N Engl J Med. 2012;366(22):2074-84.

10. Cunningham D, Allum WH, Stenning SP, Thompson JN, Van de Velde CJ, Nicolson M, et al. Perioperative chemotherapy versus surgery alone for resectable gastro-esophageal cancer. $\mathrm{N}$ Engl $\mathrm{J}$ Med. 2006;355(1):11-20.

11. Ychou M, Boige V, Pignon JP, Conroy T, Bouché O, Lebreton G, et al. Perioperative chemotherapy compared with surgery alone for resectable gastroesophageal adenocarcinoma: an FNCLCC 
and FFCD multicenter phase III trial. J Clin Oncol. 2011;29(13):1715-21.

12. Smalley SR, Benedetti JK, Haller DG, Hundahl SA, Estes NC, Ajani JA, et al. Updated analysis of SWOG-directed intergroup study 0116: a phase III trial of adjuvant radiochemotherapy versus observation after curative gastric cancer resection. J Clin Oncol. 2012;30(19):2327-33.

13. Sakuramoto S, Sasako M, Yamaguchi T, Kinoshita T, Fujii M, Nashimoto A, et al. Adjuvant chemotherapy for gastric cancer with S-1, an oral fluoropyrimidine. $\mathrm{N}$ Engl $\mathrm{J}$ Med. 2007;357(18):1810-20; erratum in: N Engl J Med. 2008;358(18):1977.

14. Noh SH, Park SR, Yang HK, Chung HC, Chung IJ, Kim SW, et al. Adjuvant capecitabine plus oxaliplatin for gastric cancer after D2 gastrectomy (CLASSIC): 5-year follow-up of an openlabel, randomised phase 3 trial. Lancet Oncol. 2014;15(12):1389-96.

15. De Angelis R, Sant M, Coleman MP, Francisci S, Baili P, Pierannunzio D, et al. Cancer survival in Europe 1999-2007 by country and age: results of EUROCARE-5-a population-based study. Lancet Oncol. 2014;15(1):23-34.

16. Mapstone N. Dataset for the histopathological reporting of oesophageal carcinoma. 2nd ed. London: Royal College of Pathologists; 2007.

17. Siewert JR, Stein HJ. Carcinoma of the cardia: carcinoma of the gastroesophageal junction-classification, pathology and extent of resection. Dis Esophagus. 1996;9(3):173-82.

18. Medical Research Council Oesophageal Cancer Working Party. Surgical resection with or without preoperative chemotherapy in oesophageal cancer: a randomised controlled trial. Lancet. 2002;359:1727-33.

19. Cunningham D, Alderson D, Nankivell MG, Stenning SP, Blazeby JM, Griffin M, et al. Toxicity, surgical complications, and short-term mortality in a randomized trial of neoadjuvant cisplatin/5FU versus epirubicin/cisplatin and capecitabine prior to resection of lower esophageal/gastroesophageal junction (GOJ) adenocarcinoma (MRC OEO5, ISRCTN01852072, CRUK 02/010). J Clin Oncol. 2014;32(15 Suppl):4014.
20. Okines AF, Langley RE, Thompson LC, Stenning SP, Stevenson L, Falk S, et al. Bevacizumab with peri-operative epirubicin, cisplatin and capecitabine (ECX) in localised gastro-oesophageal adenocarcinoma: a safety report. Ann Oncol. 2013;24(3):702-9.

21. Ozdemir BA, Karthikesalingam A, Sinha S, Poloniecki JD, Hinchliffe RJ, Thompson MM, et al. Research activity and the association with mortality. PLoS ONE. 2015;10(2):e0118253.

22. Health and Social Care Information Centre. National Oesophagogastric Cancer Audit 2013. 2013. https://www.rcseng.ac.uk/ media/docs/press_releases/national-oesophago-gastric-canceraudit-2013. Accessed 5 May 2015.

23. Department of Health. Guidance on commissioning cancer services: improving outcomes in upper gastro-intestinal cancers. London: Department of Health; 2001.

24. Allum WH, Griffin SM, Watson A, Colin-Jones D. Guidelines for the management of oesophageal and gastric cancer. Gut. 2002;50(Suppl 5):v1-23.

25. Joint Advisory Group on Gastrointestinal Endoscopy. Guidelines for the training, appraisal and assessment of trainees in gastrointestinal endoscopy and for the assessment of units for registration and re-registration. 2004. http://www.bsg.org.uk/pdf_ word_docs/jag_recommendations_2004.pdf. Accessed 30 Oct 2015.

26. Ford HE, Marshall A, Bridgewater JA, Janowitz T, Coxon FY, Wadsley J, et al. Docetaxel versus active symptom control for refractory oesophagogastric adenocarcinoma (COUGAR-02): an open-label, phase 3 randomised controlled trial. Lancet Oncol. 2014;15(1):78-86.

27. Bang YJ, Van Cutsem E, Feyereislova A, Chung HC, Shen L, Sawaki A, et al. Trastuzumab in combination with chemotherapy versus chemotherapy alone for treatment of HER2-positive advanced gastric or gastro-oesophageal junction cancer (ToGA): a phase 3, open-label, randomised controlled trial. Lancet. 2010;376(9742):687-97.

28. Cancer Genome Atlas Research Network. Comprehensive molecular characterization of gastric adenocarcinoma. Nature. 2014;513(7517):202-9. 